\title{
A new eosimiid from the latest middle Eocene in Pondaung, central Myanmar
}

\author{
MASANARU TAKAI ${ }^{1 *}$, CHIT SEIN ${ }^{2}$, TAKEHISA TSUBAMOTO ${ }^{1}$, \\ NAOKO EGI ${ }^{3}$, MAUNG MAUNG ${ }^{4}$, NOBUO SHIGEHARA ${ }^{1}$ \\ ${ }^{1}$ Primate Research Institute, Kyoto University, 41 Kanrin, Inuyama, Aichi, 484-8506 Japan \\ ${ }^{2}$ Department of Geology, Hinthada University, Myanmar \\ ${ }^{3}$ Laboratory of Physical Anthropology, Graduate School of Science, Kyoto University, Japan \\ ${ }^{4}$ Department of Geology, Mandaley University, Myanmar
}

Received 11 October 2003; accepted 15 May 2004

\begin{abstract}
A new species of eosimiid primate, cf. Eosimias paukkaungensis sp. nov., from the latest middle Eocene of Pondaung, central Myanmar is described. The specimen consists of left and right mandibular fragments preserving only the $\mathrm{M}_{3}$, so that its generic status is provisional. The cf. E. paukkaungensis fossil is much larger than homologues of the two Eosimias species from China. It is too large to be a mandible for the taxa represented by the Eosimias-like calcaneus from Pondaung, but smaller than Bahinia pondaungensis, another eosimiid of the Pondaung fauna. The discovery of cf. $E$. paukkaungensis indicates diversity of eosimiids in East and Southeast Asia during the middle Eocene.
\end{abstract}

Key words: Eosimiidae, middle Eocene, Pondaung, Myanmar (Burma)

\section{Introduction}

The phylogenetic, geographic, and chronologic origins of anthropoid primates are some of the most intriguing issues in paleoprimatology (Fleagle and Kay, 1994; Fleagle, 1999). At present, most researchers admit that the modern anthropoid clade had appeared in northern Africa by at least the late Eocene. This is based on the discovery of 'undoubted' anthropoid primates from the late Eocene to early Oligocene deposits in Fayum, such as Proteopithecus (Proteopithecidae) and Catopithecus (Oligopithecidae), whose identity was confirmed by the completeness of the postorbital septum and/or the pneumatization of the auditory bulla (Simons, 1989, 1990, 1997; Simons et al., 1994; Simons and Rasmussen, 1996). However, the phylogenetic relationship between anthropoids, such as these from Fayum, and other primate clades has not yet been fully elucidated. Although many researchers have proposed hypotheses concerning this question, there is still no consensus. One of the most likely candidates for 'protoanthropoid' is Eosimias, a small primate discovered from the middle Eocene in East Asia (Beard et al., 1994, 1996). Kay and colleagues performed cladistic analysis on many primates, including both extant and extinct taxa, and concluded that anthropoid primates probably derived from the omomyoid rather than the adapoid group, and that eosimiids are most likely primitive anthropoids (Kay and Williams, 1994; Kay et al., 1997; Ross et al., 1998).

The family Eosimiidae contains two genera, Eosimias and

* Corresponding author. e-mail: takai@pri.kyoto-u.ac.jp phone: +81-568-63-0533; fax: +81-568-63-0536

Published online 27 April 2005

in J-STAGE (www.jstage.jst.go.jp) DOI: 10.1537/ase.04S003
Bahinia. Eosimias was discovered at two localities in China: the early middle Eocene fissure fillings of Shanghuang, Jiangsu province and the late middle Eocene Heti Formation, Shanxi province (Beard et al., 1994, 1996; Tong, 1997). Thus far, many isolated teeth, a relatively complete mandibular corpus, several postcranials, and an isolated petrosal bone have been discovered (MacPhee et al., 1995; Gebo et al., 2001), although the petrosal bone cannot be assigned unambiguously to Eosimias due to the fragmentary condition of the specimen (MacPhee et al., 1995). The Bahinia specimens, on the other hand, contain maxillofacial parts and an associated lower jaw fragment (Jaeger et al., 1999), although neither postorbital closure nor pneumatization of the auditory bulla was confirmed. The discovery of Bahinia indicates that diversification of eosimiid primates had occurred by the middle Eocene of East and Southeast Asia. In addition, a small calcaneus thought to be an eosimiid was discovered in the Pondaung fauna (Gebo et al., 2002). The estimated body size of this specimen is much smaller than that of Bahinia, so the authors considered it to be another, new eosimiid (Gebo et al., 2002).

Here, we report a new eosimiid specimen from the latest middle Eocene sediments of the Pondaung Formation (Figure 1). The specimen appears to differ from other eosimiids of China and Myanmar at the specific level, but the generic status is presently provisional due to the fragmentary condition of the specimen. From the Pondaung fauna, five primate taxa belonging to two families, Amphipithecidae and Eosimiidae, have been discovered to date (Pilgrim, 1927; Colbert, 1937, 1938; Maw et al., 1979; Ciochon et al., 1985; Jaeger et al., 1998; Takai et al., 2001; Ciochon and Gunnell, 2002; Gunnell et al., 2002). Eosimiids, including Bahinia and an unnamed smaller taxon, were much smaller, probably insectivorous/frugivorous monkeys, while amphipithecids, 


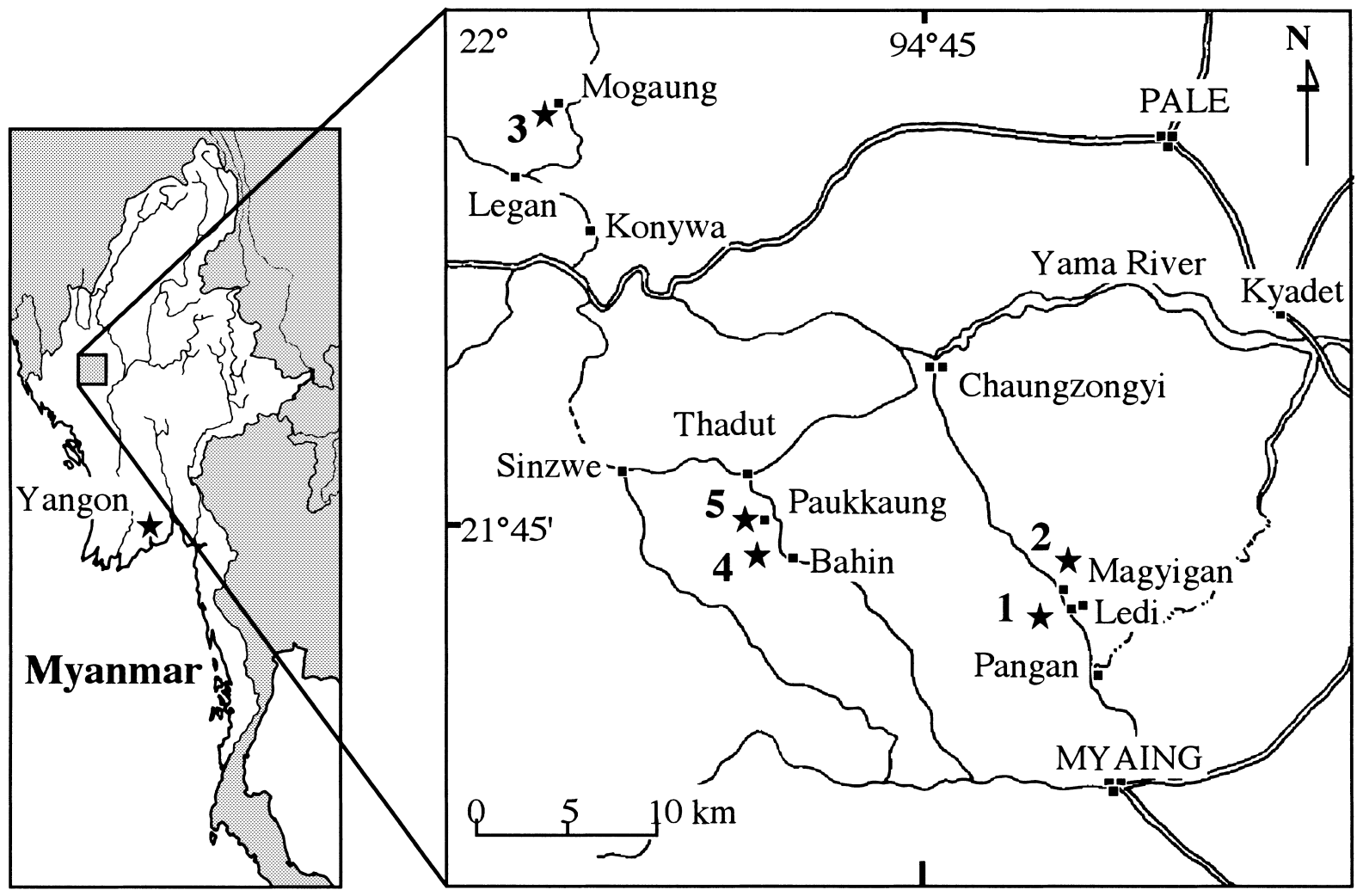

Figure 1. Map of the Pondaung area showing several primate fossil localities (stars). (1) PGN 1, type locality of Pondaungia, Pangan; (2) Taung Ni Gyin kyitchaung (PGN 2), Pangan; (3) Lema kyitchaung (Lma), type locality of Amphipithecus, Mogaung; (4) Yarshe kyitchaung (Bh 1), type locality of Bahinia and Myanmarpithecus, Bahin; (5) Paukkaung kyitchaung (Pk 2), type locality of cf. Eosimias paukkaungensis, Bahin. Kyitchaung means a small gulley in the Myanmar language.

including Myanmarpithecus, Amphipithecus, and Pondaungia, were medium to large-sized primates with a well-diversified diet (Kay et al., 2004). Although amphipithecids show some 'anthropoid-like' features in their dental and mandibular morphology, postorbital closure was confirmed to be incomplete at least in Amphipithecus (Takai et al., 2003; Takai and Shigehara, 2004). Consequently, some researchers regard amphipithecids as adapiform primates, specifically as notharctines or with notharctine-affinities (Gunnell et al., 2002), although the lower premolar morphology of amphipithecids is quite different from that of notharctine adapiforms (Takai and Shigehara, 2004).

Abbreviations are as follows: NMMP-KU, National Museum of Myanmar Paleontology-Kyoto University; NMMP, National Museum of Myanmar Primate; IVPP, Institute of Vertebrate Paleontology and Paleoanthropology, Beijing, China.

\section{Systematics}

Order Primates Linnaeus, 1785

Suborder Anthropoidea Mivart, 1864

Family Eosimiidae Beard et al., 1994

cf. Eosimias paukkaungensis sp. nov.

Holotype. NMMP-KU 1203 (NMMP 31), left edentulous mandibular corpus preserving the alveoli of $\mathrm{P}_{2}-\mathrm{M}_{3}$ (NMMP-KU 1203a) and right mandibular fragment preserving $\mathrm{M}_{3}$ (NMMP-KU 1203b) (Figure 2, Figure 3).

Type locality. Paukkaung kyitchaung ('kyitchaung' means a small gully in the Myanmar language), Pk 2 locality, Bahin area, about $2 \mathrm{~km}$ northeast of Bahin village, Myaing township, Magwe division, Myanmar (Figure 1). GPS data: $21^{\circ} 45^{\prime} 15.8^{\prime \prime} \mathrm{N}, 94^{\circ} 39^{\prime} 13.5^{\prime \prime} \mathrm{E}$.

Age and distribution. The 'Upper Member' of the Pondaung Formation, latest middle Eocene (Soe et al., 2002; Aung, 2004). The fission-track zircon date, $37.2 \pm 1.3 \mathrm{Ma}$, was obtained from the tuffaceous bed of the 'Upper Member' of the Pondaung Formation (Tsubamoto et al., 2002).

Etymology. Named from Paukkaung kyitchaung, the type locality.

Specific diagnosis. A small primate, much larger than the two other species from China, E. centennicus and E. sinensis. Compared with the Chinese species, the mandibular corpus is much wider and more robust, and $\mathrm{M}_{3}$ is markedly larger. The $\mathrm{M}_{3}$ cusps are less sharp and lower and the cristid obliqua runs more mesiodistally than in E. centennicus. Differs from Bahinia in having a much shallower and narrower mandibular corpus and in having a longitu- 

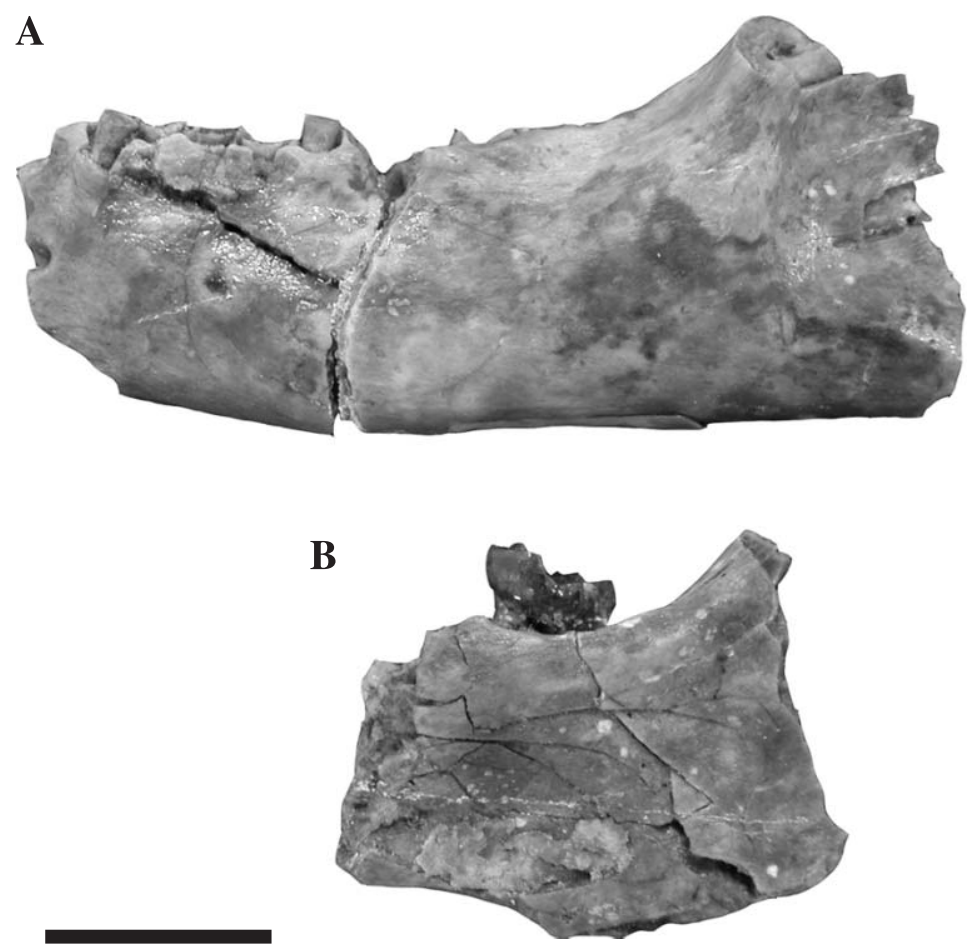

Figure 2. cf. Eosimias paukkaungensis (NMMP-KU 1203). (A) Buccal view of left mandible (NMMP-KU 1203a), and (B) lingual view of right mandibular fragment preserving $\mathrm{M}_{3}$ (NMMP-KU 1203b). Scale bar, $1 \mathrm{~mm}$.
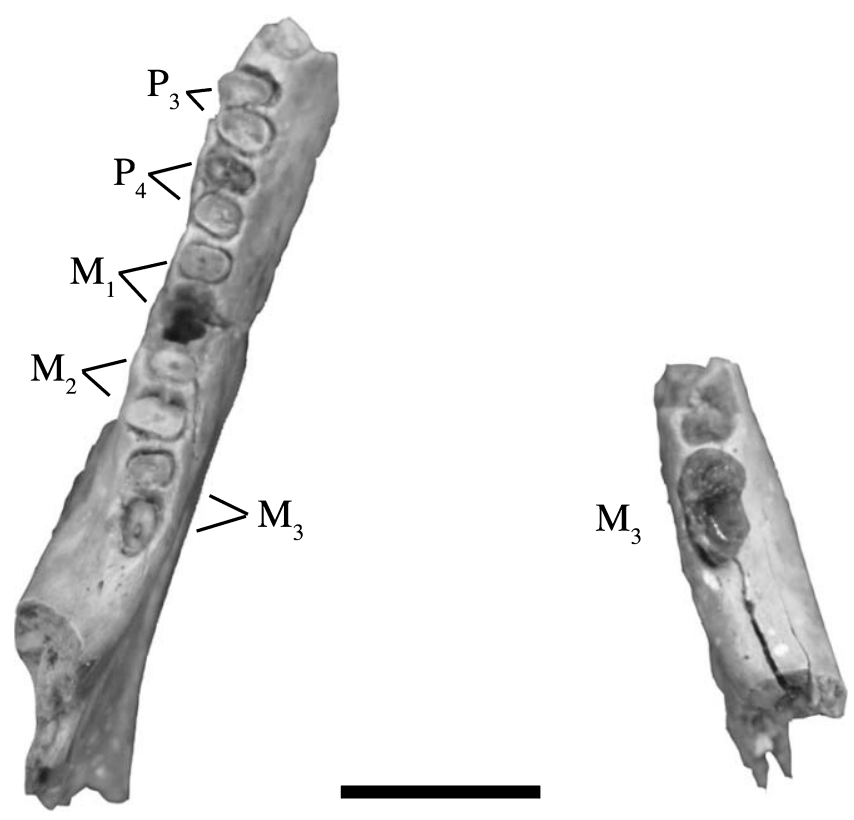

Figure 3. Occlusal view of cf. Eosimias paukkaungensis, indicating the alveoli of $\mathrm{P}_{3}-\mathrm{M}_{3}$. Scale bar, $5 \mathrm{~mm}$.

dinally shorter mandibular canine (based on alveolar dimensions). Differs from Myanmarpithecus in its significantly smaller size and shallower mandible, and in having an elevated $\mathrm{M}_{3}$ trigonid with a small paraconid. Differs from Adapoides in having a small paraconid and a lingually closed trigonid with the presence of the premetacristid on $\mathrm{M}_{3}$, and in lacking a deep talonid notch and extremely large and tapering hypoconulid on $\mathrm{M}_{3}$. Differs from omomyines in having a deeper mandibular corpus relative to $\mathrm{M}_{2}$ size. Also differs from both anaptomorphine and omomyine omomyids in the relatively large size of the paraconid on $\mathrm{M}_{3}$. Finally, differs from Tarsius eocaenus and Xanthorhysis in having a $\mathrm{M}_{3}$ trigonid lingually closed with the presence of the premetacristid, and in lacking an extreme distal heel and basal buccal cingulum on $\mathrm{M}_{3}$.

Description. cf. E. paukkaungensis is a small primate $\left(\mathrm{M}_{3}\right.$ mesiodistal length: $3.06 \mathrm{~mm}, \mathrm{M}_{3}$ buccolingual width at trigonid: $1.85 \mathrm{~mm}, \mathrm{M}_{3}$ buccolingual width at talonid: $1.68 \mathrm{~mm}$; mandibular depth at $\mathrm{M}_{2}$ lingual side: $7.18 \mathrm{~mm}$ ) with an estimated body weight of $410 \mathrm{~g}$ (see discussion below and Egi et al., 2004a, b). The estimation of $410 \mathrm{~g}$ is much larger than those of E. centennicus $(160 \mathrm{~g})$ and $E$. sinensis (140 g), but smaller than that of Bahinia (570 g, Egi et al., 2004a, b). Judging from the size and orientation of the alveoli of the left mandible, there is a small diastema between $\mathrm{P}_{2}$ and $\mathrm{P}_{3}, \mathrm{P}_{3}-\mathrm{M}_{3}$ are double-rooted, and $\mathrm{P}_{3}-\mathrm{M}_{2}$ are nearly the same size in mesiodistal length (Figure 3). $\mathrm{P}_{3}$ seems slightly obliquely oriented relative to the tooth row. On $\mathrm{M}_{3}$, the cristid obliqua runs nearly mesiodistally, terminating at the distal base of the protoconid, so the hypoflexid is very shallow. There is no basal buccal cingulid on $\mathrm{M}_{3}$ (Figure 4). The $\mathrm{M}_{3}$ trigonid is nearly triangular in occlusal view, retaining the paraconid, protoconid, and metaconid cusps and is closed lingually 
by the premetacristid. The trigonid is much more elevated and slightly wider, but shorter, than the talonid. An indistinct paraconid is located at the midline of the paralophid. The protolophid runs slightly obliquely, so that the protoconid is located slightly mesial to the metaconid. The $\mathrm{M}_{3}$ talonid has three low cusps, the hypoconid, entoconid, and hypoconulid. The hypoconulid, which is located at the midline of the tooth, protrudes posteriorly. The mandibular corpus is nearly straight or 'flat-plated' rather than medially curved. The 'prominentia lateralis,' the anterior margin of the vertical mandibular ramus, is well developed, forming a distinct masseteric fossa. A relatively large mental foramen is located just below $\mathrm{P}_{2}$.

\section{Comparisons with Other Eosimiids}

In E. centennicus, the $\mathrm{M}_{3}$ trigonid bears a remarkably large, cuspidate paraconid, which is well separated mesially from the metaconid by a deep notch (Beard et al., 1996). In contrast, in cf. E. paukkaungensis the paraconid is not cuspidate but indistinct, forming a continuous crest (Figure 4, Figure 5). The possession of the paraconid is generally considered to be a primitive character state in primate evolution, and most anthropoids have either no or a much reduced $\mathrm{M}_{3}$ paraconid. Thus, concerning the reduction of the paraconid,
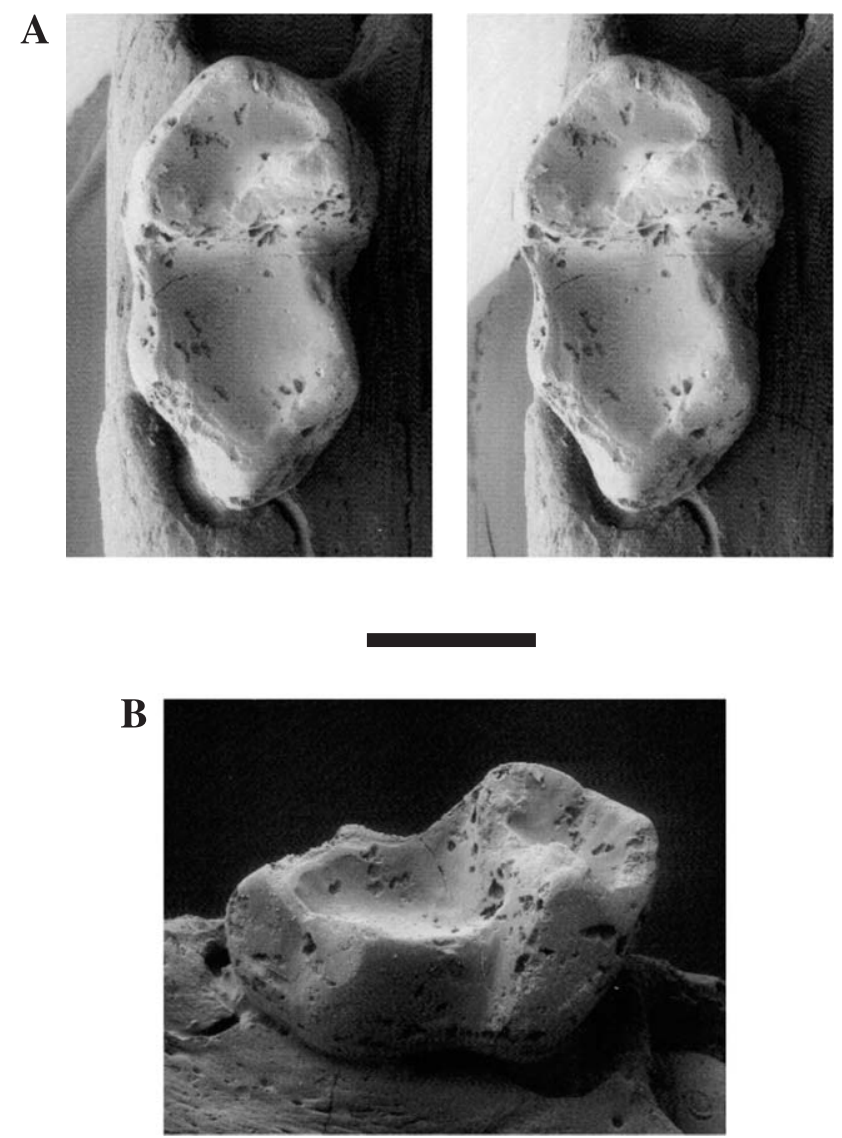

Figure 4. Right $\mathrm{M}_{3}$ of cf. Eosimias paukkaungensis (NMMP-KU 1203). (A) Occlusal (stereo pair), and (B) buccal views (scanning electron micrograph photo). Scale bar, $1 \mathrm{~mm}$. cf. E. paukkaungensis is more derived than E. centennicus, although still with a large paraconid. Despite the difference in $\mathrm{M}_{3}$ trigonid construction between E. centennicus and cf. E. paukkaungensis, the structure of the $\mathrm{M}_{3}$ talonid is similar in both species: the hypoconulid lobe is highly abbreviated and the distolingual margin of the talonid is relatively reduced as in some basal anthropoids. In Bahinia, $\mathrm{M}_{3}$ has not yet been discovered, but the $\mathrm{M}_{1}$ trigonid is well preserved. A small paraconid is located at the mesiolingual position of the trigonid, and the paraconid and metaconid are connected by the premetacristid with a shallow notch at midpoint. Therefore, it is deduced that the $\mathrm{M}_{3}$ trigonid of Bahinia is rather reduced, with the metaconid connected to the paraconid by the premetacristid.

As mentioned above, the estimated body weight of cf. $E$. paukkaungensis $(410 \mathrm{~g})$ is much larger than that of $E$. centennicus $(160 \mathrm{~g})$ and E. sinensis $(140 \mathrm{~g})$, but smaller than that of Bahinia $(570 \mathrm{~g})$. However, the body weights of the latter two species were estimated from $\mathrm{M}_{1-2}$ rather than $\mathrm{M}_{3}$ size (Egi et al., 2004b). Nevertheless, cf. E. paukkaungensis is certainly intermediate in body size between the two species of Eosimias from China and Bahinia from Myanmar. Although the tooth sizes of $\mathrm{P}_{3}-\mathrm{M}_{2}$ are unknown in $\mathrm{cf}$. $E$. paukkaungensis, the mesiodistal length of $\mathrm{M}_{2}$ can be estimated to be $2.6 \mathrm{~mm}$, based on the size and placement of the preserved alveoli of $\mathrm{M}_{1}$ and $\mathrm{M}_{3}$ (Figure 3). Figure 6 shows scatterplots of mandibular depth beneath $\mathrm{M}_{2}$ against the

A
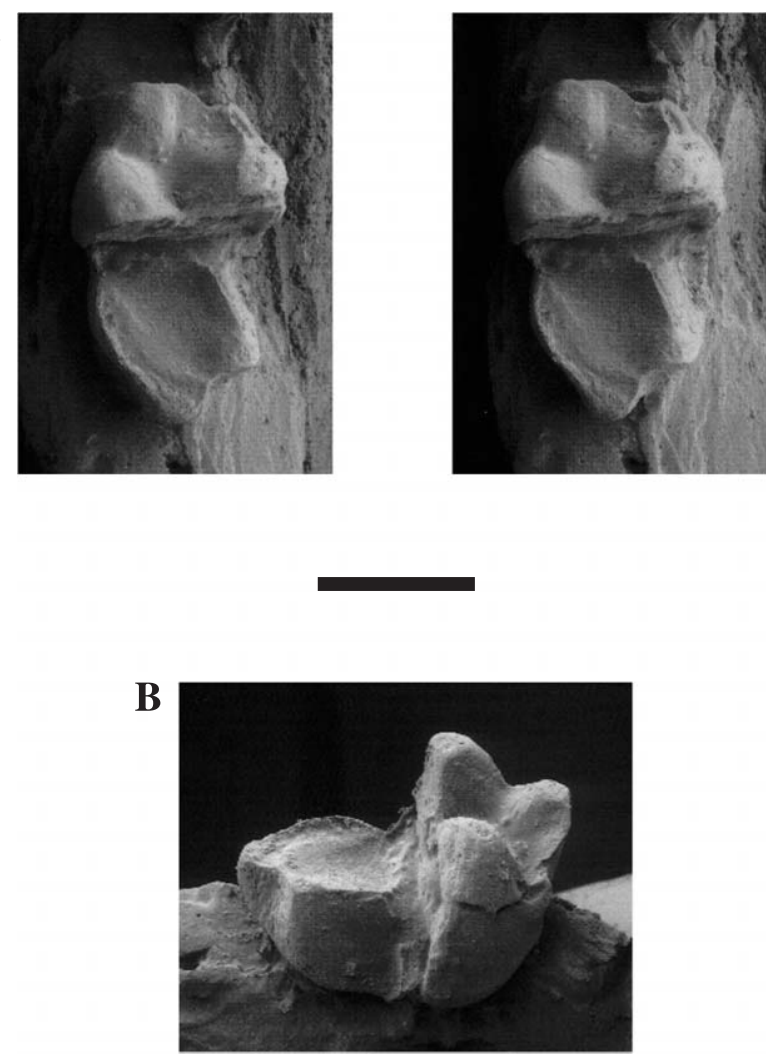

Figure 5. Right $\mathrm{M}_{3}$ of Eosimias centennicus (IVPP 11000). (A) Occlusal (stereo pair), and (B) lingual views (scanning electron micrograph photo). Scale bar, $1 \mathrm{~mm}$. 
mandibular depth $(\mathrm{mm})$

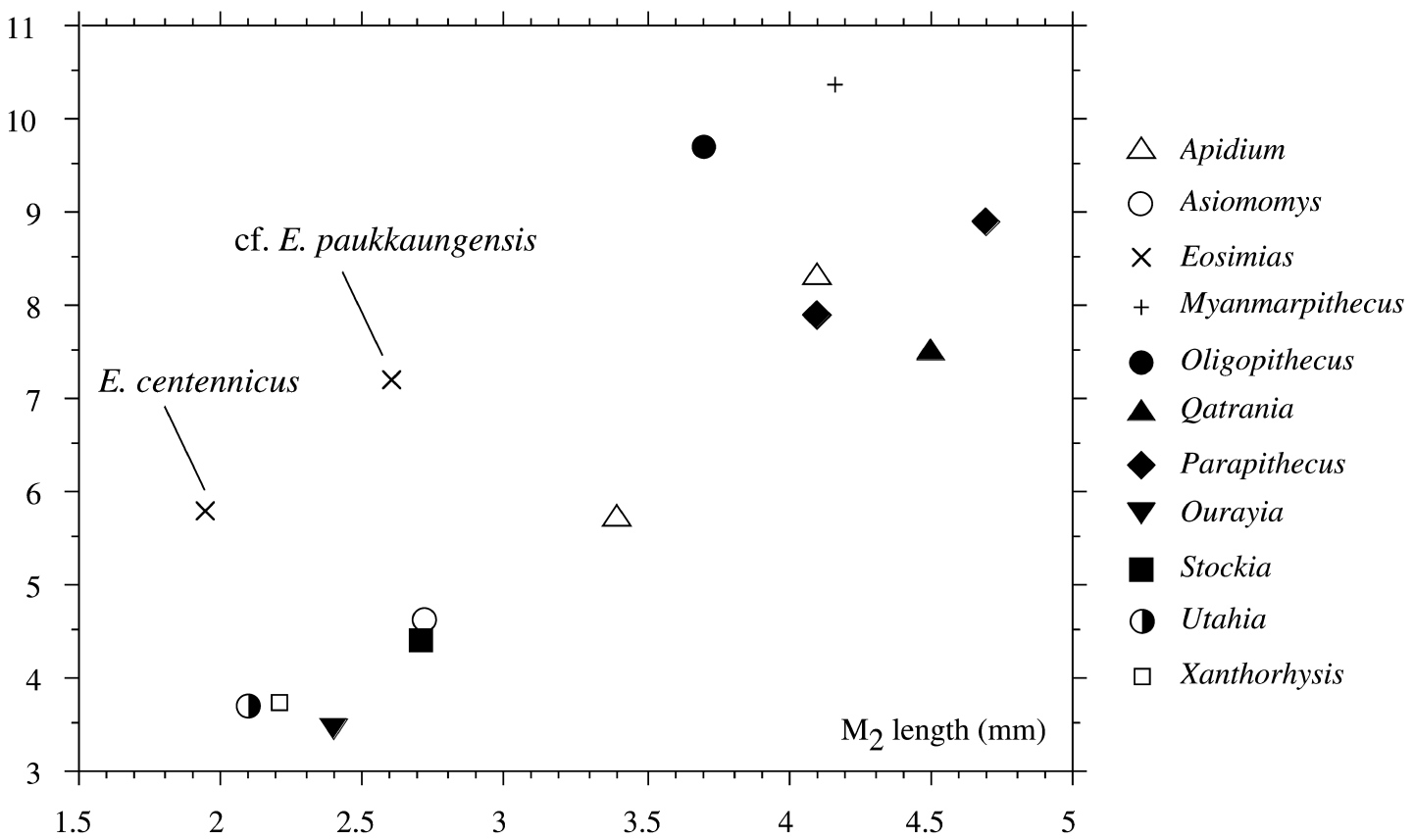

Figure 6. Scatterplots of lingual mandibular depth beneath $\mathrm{M}_{2}$ versus mesiodistal length of $\mathrm{M}_{2}$ in several primate taxa discussed in the text. Note that the mesiodistal length of $\mathrm{M}_{2}$ of $\mathrm{cf}$. E. paukkaungensis was estimated from the preserved $\mathrm{M}_{1}-\mathrm{M}_{3}$ alveoli. The measurements were adopted from Gazin (1958), Simons (1961, 1962), Szalay (1976), Kay et al. (1981), Simons and Kay (1983), Wang and Li (1990), Beard et al. (1994, 1996) and Takai et al. (2001).

mesiodistal length of $\mathrm{M}_{2}$. The relative mandibular depth in cf. E. paukkaungensis is, together with E. centennicus, Oligopithecus (Oligopithecidae), and Myanmarpithecus (Amphipithecidae), larger than that of omomyines (Asiomomys, Ourayia, Utahia, Stockia), Xanthorhysis, and parapithecids (Apidium, Parapithecus, Qatrania).

We provisionally classify NMMP-KU 1203 in the genus Eosimias rather than Bahinia, which was also discovered in the Pondaung fauna, based on the morphology of the mandibular corpus. The type specimen of Bahinia pondaungensis was discovered in 1998 by the Myanmar-France Joint Expedition Team (MFJET) at the Bh 1 locality, about $2 \mathrm{~km}$ south of Pk 2. The type consists of right (NMMP 15) and left (NMMP 14) maxillae and a right mandibular fragment preserving $\mathrm{P}_{2}-\mathrm{M}_{1}$ (NMMP 16 ), all of which belong to a single individual (Jaeger et al., 1999). Of note, a complementary mandibular fragment preserving the left $\mathrm{C}_{1}-\mathrm{M}_{1}$ and right $\mathrm{I}_{2}-$ $\mathrm{C}_{1}$ (NMMP 13 = NMMP-KU 0129, Figure 7B), which perfectly joins NMMP 16, the right mandibular fragment, at the break, was collected independently by another team, the Myanmar-Japan Pondaung Paleontological Expedition Team (MJPPE), during the 1998 field season (Ciochon and Gunnell, 2002). NMMP-KU 0129 consists of the left mandibular corpus and the anterior part of the right mandible, which became fused through fossilization, although the mandibular symphysis was certainly unfused during the animal's lifetime.

The tooth crown of the left canine of NMMP-KU 0129 is damaged so that the exact height and morphology of the tooth is unknown. However, the preserved root indicates that
A

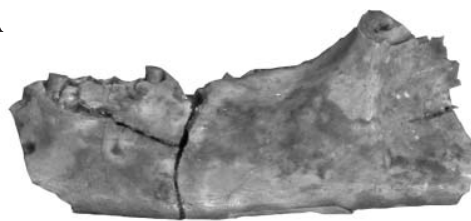

B
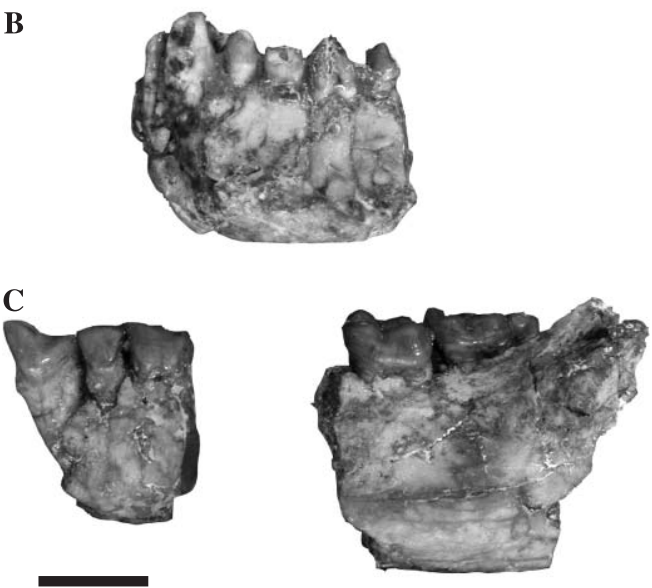

Figure 7. Comparisons of mandibles of the small- to mediumsized Pondaung primates. All are left mandibular specimens (buccal views). (A) cf. Eosimias paukkaungensis sp. nov. (NMMP-KU 1203), (B) Bahinia pondaungensis (NMMP-KU 0129), and (C) Myanmarpithecus yarshensis (NMMP-KU 0001). Scale bar, $5 \mathrm{~mm}$. 
the mandibular canine was much larger than $\mathrm{P}_{2}$; the root is very long, almost reaching the base of the mandible in Bahinia (Figure 7B). In E. centennicus, in contrast, the lower canine is not as large as in Bahinia (Beard et al., 1996). Thus, one of the most obvious morphological features distinguishing Bahinia and Eosimias seems to be the size of the lower canine root. Although in NMMP-KU 1203 neither the canine root nor the alveolus are preserved, judging from the shape of the anterior part of the remaining mandibular corpus, NMMP-KU 1203 is unlikely to retain such a large, long mandibular canine as in Bahinia (Figure 8).

Due to the lack of evidence, however, it is difficult to dismiss the possibility that NMMP-KU 1203 may belong to Bahinia: this specimen could be either a female individual of B. pondaungensis or a new species of Bahinia. Sexual dimorphism has been demonstrated in the lower canines and mandibular corpus of Catopithecus and Proteopithecus, early anthropoids from the late Eocene of Fayum (Simons, 1995; Simons and Rasmussen, 1996; Simons et al., 1999). In Catopithecus, according to these studies, the mandibular corpora of both sexes are quite similar in shape but slightly shallower in females (Simons, 1995; Simons and Rasmussen, 1996). In the two Myanmar eosimiids, in contrast, the overall morphology of the mandibular corpus seems to be quite different; in $B$. pondaungensis the mandibular corpus is about equal in depth anteriorly to the symphysis, whereas in NMMP-KU 1203 the corpus appears to shallow anteriorly (Figure 8) as in Chinese Eosimias. It is unlikely that $B$. pondaungensis and NMMP-KU 1203 are male and female individuals of the same species.

In this paper we classify NMMP-KU 1203 as cf. Eosimias paukkaungensis, emphasizing the morphology of the mandibular corpus. Although both $\mathrm{M}_{1}$ of $B$. pondaungensis and $\mathrm{M}_{3}$ of NMMP-KU 1203 possess a distinct paraconid in the trigonid, this is not a comparison of the serial homologue but of different teeth, the $\mathrm{M}_{1}$ and $\mathrm{M}_{3}$. The generic status of NMMP-KU 1203 would be determined by the future discovery of other dentition.

On the other hand, a very small right calcaneus was discovered by the MJPPE from the $\mathrm{Pk} 2$ locality during the 1999 field season. Gebo et al. (2002) identified this specimen, NMMP 23 (= NMMP-KU 0961), as an Eosimias-like primate, due to similarity with the Eosimias calcaneus from China. The estimated body size for this calcaneus is $110.7 \mathrm{~g}$

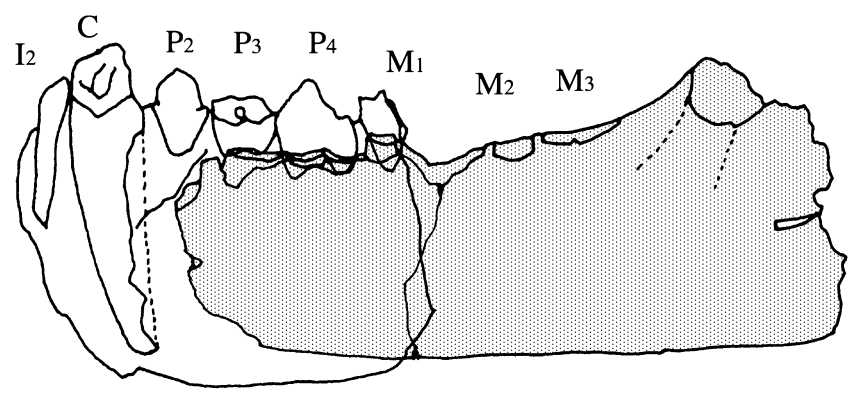

Figure 8. Comparison of the mandibular corpora of Bahinia pondaungensis (NMMP-KU 0129, white) and cf. Eosimias paukkaungensis (shaded). Note the basal curve of the anterior part of the mandible. (range 52.3-183.4 g), which ranks in the largest size class for Eosimias specimens at Shanghuang (range 75-120 g) (Gebo et al., 2001). This estimate of $110.7 \mathrm{~g}$ is much smaller than $410 \mathrm{~g}$, the estimated body weight of cf. E. paukkaungensis based on $\mathrm{M}_{3}$ size, and $570 \mathrm{~g}$, that of $B$. pondaungensis based on $\mathrm{M}_{1}$ (Egi et al., 2004b). NMMP 23, NMMP-KU 1203 , and $B$. pondaungensis should be regarded as different species at present. There seem to be three eosimiids of different sizes in the Pondaung fauna.

\section{Comparisons with Other Paleogene Primates in East Asia}

To date, several fossil primates have been identified from the Paleogene of Asia. Some specimens lack a preserved $\mathrm{M}_{3}$ and are too fragmentary to compare with cf. E. paukkaungensis, while others preserve comparable portions. Among the Paleogene adapiforms from Asia, Hoanghonius and Wailekia (Sivaladapinae), Adapoides (Adapinae), and Panobius (Cercamoniinae) are comparable with cf. E. paukkaungensis. Hoanghonius was discovered from the middle Eocene in the Yuanqu basin, Shanxi Province, China, and Wailekia from the upper Eocene in the Krabi basin, Thailand (Suteethorn et al., 1988; Ducrocq et al., 1995; Ducrocq, 1998). Adapoides was collected from the middle Eocene Shanghuang fissure fillings, at the same locality as E. sinensis (Beard et al., 1996). Unlike cf. E. paukkaungensis, both Adapoides and Hoanghonius have a very large, posteriorly elongated heel at the $\mathrm{M}_{3}$ talonid (Beard et al., 1994; Gingerich et al., 1994). In Wailekia, the $\mathrm{M}_{3}$ talonid is not as posteriorly elongated as in Adapoides and Hoanghonius, but in contrast to cf. E. paukkaungensis, the $\mathrm{M}_{3}$ trigonid is very compressed mesiodistally and its occlusal outline is nearly rectangular (Ducrocq et al., 1995; Ducrocq, 1998). Conversely, in Panobius, which was discovered from the middle Eocene Kuldana Formation, Pakistan, the paraconid is situated lingually, just mesial to the metaconid, and there is a distinct mesiolingual cingulid on the $\mathrm{M}_{3}$ (Russell and Gingerich, 1987). Thus, none of the Asian adapiforms shows the $\mathrm{M}_{3}$ trigonid pattern seen in cf. E. paukkaungensis, suggesting a relatively distant relationship to the latter.

Among three Paleogene omomyoids discovered in Asia, Macrotarsius, Asiomomys, and Kohatius, the former two are known only by fragmentary isolated teeth (Russell and Gingerich, 1980, 1987; Beard and Wang, 1991; Beard et al., 1994; Thewissen et al., 1997). Asiomomys (Utahiini, Omomyinae) was discovered from the Eocene in Huadian, Jiling province, China (Beard and Wang, 1991), and the type specimen consists of the right mandible, with preserved $\mathrm{P}_{3}$ and $\mathrm{M}_{2-3}$. The $\mathrm{M}_{3}$ of Asiomomys differs from that of cf. $E$. paukkaungensis in having a mesiodistally compressed trigonid, a very wide talonid, a well-developed talonid notch, a distinct mesiobuccal cingulid, and a large hypoconulid lobe. Moreover, in Asiomomys, the $\mathrm{M}_{3}$ trigonid is not as elevated as in cf. E. paukkaungensis, and the mandibular corpus is very shallow relative to $\mathrm{M}_{2}$ length (Figure 6).

Two Paleogene tarsiids have been reported from the middle Eocene of China. Tarsius eocaenus was discovered from the middle Eocene Shanghuang fissure fillings, at the same locality as E. sinensis and Adapoides (Beard et al., 1994), 
and Xanthorhysis tabrumi also from the middle Eocene Heti Formation, Yuanqu basin, Shanxi province (Beard, 1998). In both T. eocaenus and Xanthorhysis, the $\mathrm{M}_{3}$ trigonid is mesiodistally compressed and lingually open, a distinct paraconid is located at the lingual side, and the talonid is much longer than the trigonid with a large hypoconulid lobe. Moreover, in Xanthorhysis, the mandibular corpus is very shallow relative to $\mathrm{M}_{2}$ length (Figure 6). All these morphological features indicate that $\mathrm{cf}$. E. paukkaungensis should not be included in the Tarsiidae.

\section{Discussion}

Although the cf. E. paukkaungensis specimen is fragmentary, with the $\mathrm{M}_{3}$ being the only known crown element among the dentition, the morphology of the mandibular corpus and $\mathrm{M}_{3}$ structure indicate that this animal belongs to the family Eosimiidae rather than to other Paleogene primate groups, such as adapoids, omomyoids, and tarsiids. The discovery of Bahinia revealed that there are three middle Eocene localities yielding eosimiids in eastern Asia: the Shanghuang (Jiangsu province) and Yuanqu (Shangxi province) faunas in China and the Pondaung fauna in Myanmar. Among the fauna from these three localities, the Pondaung fauna is more distantly separated from fauna of the other two Chinese localities both geographically and chronologically. At present the Pondaung area is located at a latitude $10-12^{\circ}$ south of the other two Chinese localities. Even in the middle Eocene, Pondaung should have been located at a relatively lower latitude, suggestive of a warmer, tropical environment. Indeed, detailed analysis of the Pondaung mammal fauna demonstrates that the paleoenvironment was characterized by subtropical/tropical rainforest with large rivers, which were located near the Tethys Sea (Tsubamoto et al., 2004).

Chronologically, the Pondaung fauna is certainly younger than the two Chinese faunas. Although no absolute age has been reported thus far for the Shanghuang and Zhaili faunas, the former is considered somewhat older than the latter, based on comparisons of mammalian fossils discovered from both faunas (Beard et al., 1996; Tsubamoto et al., 2004). In addition, the mammalian fossils from the Shanghuang fissure fillings appear to represent the Irdinmanhan and early Sharamurunian Asian land mammal ages (ALMA). As the Irdinmanhan ALMA can be correlated to the Bridgerian and early Uintan North American land mammal ages (NALMA), the boundary of which is considered to be about $46 \mathrm{Ma}$, the Shanghuang fauna is estimated to be about $45 \mathrm{Ma}$ (Beard et al., 1994). On the other hand, the absolute age of the Pondaung Formation was calculated as 37.2 $\mathrm{Ma}$ based on the fission-track method (Tsubamoto et al., 2002). The Pondaung fauna seems to be about seven to eight million years younger than the Shanghuang fauna (Holroyd and Ciochon, 1994; Ciochon and Gunnell, 2002).

In northern East Asia, such as Mongolia and northern China, the primate fossil record is intermittent after the late Eocene. Therefore, eosimiids seem to have originated at mid-latitude eastern Asia and moved their distribution to the southern, low-latitude area during the late Eocene, when global cooling occurred, resulting in a deterioration of the mid-latitude environment even in East Asia. South and Southeast Asia is likely to have maintained a relatively warm, tropical environment throughout the late middle Eocene to early Oligocene age (Marivaux et al., 2001, 2002; Tsubamoto et al., 2004), and could have been a refugium for eosimiids, which were adapted to tropical environment.

Besides eosimiids, three amphipithecids, Pondaungia, Amphipithecus, and Myanmarpithecus, have been discovered in the Pondaung fauna (Ciochon and Gunnell, 2002). The $\mathrm{Pk} 2$ locality in particular has yielded Pondaungia, Amphipithecus, Myanmarpithecus, and cf. E. paukkaungensis, demonstrating the coexistence of these primates as early as the latest middle Eocene in Southeast Asia. Recently, amphipithecids were reported from the lower Oligocene of the Bugti Hills, southern Pakistan (Marivaux et al., 2001, 2002). The Bugti fauna, which has long been regarded as early to middle Miocene but has been revised to be the early Oligocene through the early early Miocene, is notable for producing not only amphipithecids but also oligopithecids, sivaladapids, and cheirogaleids. The northern African and southeastern Asian faunas share these primate groups. Oligopithecids have been discovered from the late Eocene/early Oligocene Fayum fauna (Simons, 1962, 1989, 1990), and sivaladapids have been reported from the late Eocene Krabi fauna, Thailand (Ducrocq et al., 1995), Gongkang fauna, Guangxi Province, China (Qi and Beard, 1998) and from some late Miocene sites in China (Gingerich et al., 1994, Qi and Beard, 1998). The Bugti fauna actually demonstrates faunal interaction between the African and Asian continents.

The late middle Eocene to early Oligocene of southern Asia could be a platform for the evolution of early anthropoids and/or early catarrhines, which might have moved from eastern Asia or northern Africa. The paleoprimatological research areas in southern Asia, such the Pondaung, Krabi, and Bugti, may hold the answer to the question of anthropoid origins or catarrhine evolution in the Old World continent.

\section{Acknowledgments}

We would like to thank Brigadier General Than-Tun, Major Bo Bo, and other staff of the International Affair and Research Department, Ministry of Defense, Myanmar, for their cooperation with the field research. We are grateful to Drs H. Suzuki, Aye Ko Aung, Soe Thura Tun, and Aung Naing Soe for their geological/paleontological work in the field. We also thank Drs Pat Holroyd, Chris Beard, and J.-J. Jaeger for providing critical comments on the manuscript. Dr Chris Beard kindly provided us the Eosimias casts that his joint team collected in China. For access to fossil primate specimens under their care, we thank Drs J. Alexander and M.C. McKenna of the American Museum of Natural History, New York, and Dr E. Simons of Duke University Primate Center. This research was supported by Overseas Scientific Research Fund (No. 14405019) and Grant-in-Aid for COE Research (No. 10CE2005) from the Ministry of Education, Culture, Science and Sport, Japan. 


\section{References}

Aung A.K. (2004) The primate-bearing Pondaung Formation in the upland area, northern Central Myanmar. In: Ross C.F. and Kay R.F. (eds.), Anthropoid Origins: New Visions. Kluwer Academic/Plenum Publishers, New York, pp. 205-217.

Beard K.C. (1998) A new genus of Tarsiidae (Mammalia: Primates) from the middle Eocene of Shanxi Province, China, with notes on the historical biogeography of tarsiers. Bulletin of Carnegie Museum of Natural History, 34: 260-277.

Beard K.C. and Wang B. (1991) Phylogenetic and biogeographic significance of the tarsiiform primate Asiomomys changbaicus from the Eocene of Jilin Province, People's Republic of China. American Journal of Physical Anthropology, 85: 159166.

Beard K.C., Qi T., Dawson M.R., Wang B., and Li C. (1994) A diverse new primate fauna from middle Eocene fissure-fillings in southeastern China. Nature, 368: 604-609.

Beard K.C., Tong Y., Dawson M.R., Wang J., and Huang X. (1996) Earliest complete dentition of an anthropoid primate from the Late Middle Eocene of Shanxi Province, China. Science, 272: $82-85$.

Ciochon R.L. and Gunnell G.F. (2002) Chronology of primate discoveries in Myanmar: influences on the anthropoid origins debate. Yearbook of Physical Anthropology, 45: 2-35.

Ciochon R.L., Savage D.E., Tint T., and Maw B. (1985) Anthropoid origins in Asia? New discovery of Amphipithecus from the Eocene of Burma. Science, 229: 756-759.

Colbert E.H. (1937) A new primate from the upper Eocene Pondaung Formation of Burma. American Museum Novitates, 951: 1-18.

Colbert E.H. (1938) Fossil mammals from Burma in the American Museum of Natural History. Bulletin of the American Museum of Natural History, 74: 255-436.

Ducrocq S. (1998) Eocene primates from Thailand: are Asian anthropoideans related to African ones? Evolutionary Anthropology, 7: 97-104.

Ducrocq S., Jaeger J-J., Chaimanee Y., and Suteethorn V. (1995) New primates from the Paleogene of Thailand, and the biogeographical origin of anthropoids. Journal of Human Evolution, 28: 477-485.

Egi N., Soe Thura Tun, Takai M., Shigehara N., and Tsubamoto T. (2004a) Geographical and body size distributions of the Pondaung primates with a comment on the taxonomic assignment of NMMP 20, postcranium of an amphipithecid. Anthropological Science, 112: 67-74.

Egi N., Takai M., Shigehara N., and Tsubamoto T. (2004b) Body mass estimation of the possible primitive anthropoids: problems on reliability of the estimation for the fossils without closely related extant primates. International Journal of Primatology, 25: 211-236.

Fleagle J.G. (1999) Primate Adaptation and Evolution. Academic Press, San Diego.

Fleagle J.G. and Kay R.F. (1994) Anthropoid origins: past, present, and future. In: Fleagle J.G. and Kay R.F. (eds.), Anthropoid Origins. Plenum Press, New York, pp. 675-698.

Gazin C.L. (1958) A review of the middle and upper Eocene primates of North America. Smithsonian Miscellaneous Collections, Volume 136, pp. 1-112.

Gebo D.L., Dagosto M., Beard K.C., and Qi T. (2001) Middle Eocene primate tarsals from China: implications for haplorrhine evolution. American Journal of Physical Anthropology, 116: 83-107.

Gebo D.L., Gunnell G.F., Ciochon R.L., Takai M., Tsubamoto T., and Egi, N. (2002) New eosimiid primate from Myanmar. Journal of Human Evolution, 43: 549-553.

Gingerich P.D., Holroyd P., and Ciochon R. (1994) Rencunius zhoui, new primate from the Late Middle Eocene of Henan, China, and a comparison with some early Anthropoidea. In:
Fleagle J.G. and Kay R.F. (eds.), Anthropoid Origins. Plenum Press, New York, pp. 163-177.

Gunnell G.F., Ciochon R.L., Gingerich P.D., and Holroyd P.A. (2002) New assessment of Pondaungia and Amphipithecus (Primates) from the Late Middle Eocene of Myanmar, with a comment on 'Amphipithecidae.' Contributions from the Museum of Paleontology, University of Michigan, Volume 30, pp. 337-372.

Holroyd P.A. and Ciochon R.L. (1994) Relative ages of Eocene primate-bearing deposits of Asia. In: Fleagle J.G. and Kay R.F (eds.), Anthropoid Origins. Plenum Press, New York, pp. 123-141.

Jaeger J.-J., Soe U.A.N., Aung U.A.K., Benammi M., Chaimanee Y., Ducrocq R.-M., Tun C.T., Thein U.T., and Ducrocq S. (1998) New Myanmar middle Eocene anthropoids. An Asian origin for catarrhines? Comptes Rendus de l'Académie des Sciences, Série 3, 321: 953-959.

Jaeger J.-J., Thein T., Benammi M., Soe A.N., Lwin T., Tun T., Wai S., and Ducrocq S. (1999) A new primate from the middle Eocene of Myanmar and the Asian early origin of anthropoids. Science, 286: 528-530.

Kay R.F. and Williams B.A. (1994) Dental evidence for anthropoid origins. In: Fleagle J.G. and Kay R.F. (eds.), Anthropoid Origins. Plenum Press, New York, pp. 361-445.

Kay R.F., Fleagle J.G., and Simons E.L. (1981) A revision of the Oligocene apes of the Fayum Province, Egypt. American Journal of Physical Anthropology, 55: 293-322.

Kay R.F., Ross C., and Williams B.A. (1997) Anthropoid origins. Science, 275: 797-804.

Kay R.F., Schmitt, D., Vinyard C.J., Perry J.M.G., Shigehara N., Takai M., and Egi N. (2004) The paleobiology of Amphipithecidae, South Asian late Eocene primates. Journal of Human Evolution, 46: 3-24.

MacPhee R.D.E., Beard K.C., and Qi T. (1995) Significance of primate petrosal from Middle Eocene fissure-fillings at Shanghuang, Jiangsu Province, People's Republic of China. Journal of Human Evolution, 29: 501-514.

Marivaux L., Welcomme J.-L., Antoine P.-O., Métais G., Baloch I.M., Benammi M., Chaimanee Y., Ducrocq S., and Jaeger J.J. (2001) A fossil lemur from the Oligocene of Pakistan. Science, 294: 587-591.

Marivaux L., Welcomme J.-L., Ducrocq S., and Jaeger J.-J. (2002) Oligocene sivaladapid primate from Bugti Hills (Balochistan, Pakistan) bridges the gap between Eocene and Miocene adapiform communities in Southern Asia. Journal of Human Evolution, 42: 379-388.

Maw B., Ciochon R.L., and Savage D.E. (1979) Late Eocene of Burma yields earliest anthropoid primate, Pondaungia cotteri. Nature, 282: 65-67.

Pilgrim G.E. (1927) A Sivapithecus palate and other primate fossils from India. Palaeontologia Indica, New Series, 14: 1-26.

Qi T. and Beard K.C. (1998) Late Eocene sivaladapid primate from Guangxi Zhuang Autonomous Region, People's Republic of China. Journal of Human Evolution, 35: 211-220.

Ross C., Williams B.A., and Kay R.F. (1998) Phylogenetic analysis of anthropoid relationships. Journal of Human Evolution, 35: $221-306$.

Russell D.E. and Gingerich P.D. (1980) Un nouveau Primate omomyide dans l'Éocène du Pakistan. Comptes rendus des séances de l'Académie des sciences, Série D, 291: 621-624.

Russell D.E. and Gingerich P.D. (1987) Nouveaux Primates de l'Éocène du Pakistan. Comptes rendus de l'Académie des sciences. Série 2, 304: 209-214.

Simons E.L. (1961) The dentition of Ourayia: its bearing on relationships of omomyid prosimians. Postilla, 54: 1-20.

Simons E.L. (1962) Two new primate species from the African Oligocene. Postilla, 64: 1-12.

Simons E.L. (1989) Description of two genera and species of Late Eocene Anthropoidea from Egypt. Proceedings of the 
National Academy of Sciences of the United States of America, 86: 9956-9960.

Simons E.L. (1990) Discovery of the oldest known anthropoidean skull from the Paleogene of Egypt. Science, 247: 1567-1569.

Simons E.L. (1995) Skulls and anterior teeth of Catopithecus (Primates: Anthropoidea) from the Eocene and anthropoid origins. Science, 268: 1885-1888.

Simons E.L. (1997) Preliminary description of the cranium of Proteopithecus sylviae, an Egyptian late Eocene anthropoidean primate. Proceedings of the National Academy of Sciences of the United States of America, 94: 14970-14975.

Simons E.L. and Kay R.F. (1983) Qatrania, new basal anthropoid primate from the Fayum, Oligocene of Egypt. Nature, 304: 624-626.

Simons E.L. and Rasmussen D.T. (1996) Skull of Catopithecus browni, an early Tertiary catarrhine. American Journal of Physical Anthropology, 100: 261-292.

Simons E.L., Rasmussen D.T., Bown T.M., and Chatrath P.S. (1994) The Eocene origin of anthropoid primates: adaptation, evolution, and diversity. In: Fleagle J.G. and Kay R.F. (eds.), Anthropoid Origins. Plenum Press, New York, pp. 179-201.

Simons E.L., Plavcan J.M., and Fleagle J.G. (1999) Canine sexual dimorphism in Egyptian Eocene anthropoid primates: Catopithecus and Proteopithecus. Proceedings of the National Academy of Sciences of the United States of America, 96: 2559-2562.

Soe A.N., Myitta, Tun S.T., Aung A.K., Thein T., Marandat B., Ducrocq S., and Jaeger J.-J. (2002) Sedimentary facies of the late Middle Eocene Pondaung Formation (central Myanmar) and the palaeoencivornments of its anthropoid primates. Comptes Rendus Palevol, 1: 153-160.

Suteethorn V., Buffetaut E., Helmcke-Ingavat R., Jaeger J.-J., and Jongkanjanasoontorn Y. (1988) Oldest known Tertiary mammals from South East Asia: Middle Eocene primate and anthracotheres from Thailand. Neues Jahrbuch für Geologie und Paläontologie, Monatsheft, H9: 563-570.

Szalay F.S. (1976) Systematics of the Omomyidae (Tarsiiformes, Primates): taxonomy, phylogeny, and adaptation. Bulletin of the American Museum of Natural History, 156: 1-449.

Takai M. and Shigehara N. (2004) The Pondaung primates, enigmatic "possible anthropoids" from the latest middle Eocene, central Myanmar. In: Ross C. and Kay R.F. (eds.), Anthropoid Origins: New Visions. Kluwer Academic/Plenum Publishers, New York, pp. 283-321.

Takai M., Shigehara N., Aung A.K., Soe A.N., Tun S.T., Tsubamoto T., and Thein T. (2001) A new anthropoid from the latest middle Eocene of Pondaung, Central Myanmar. Journal of Human Evolution, 40: 393-409.

Takai M., Shigehara N., Egi N., and Tsubamoto T. (2003) Endocranial cast and morphology of the olfactory bulb of Amphipithecus mogaungensis (latest middle Eocene of Myanmar). Primates, 44: 137-144.

Thewissen J.G., Hussain S.T., and Arif M. (1997) New Kohatius (Omomyidae) from the Eocene of Pakistan. Journal of Human Evolution, 32: 473-477.

Tong Y. (1997) Middle Eocene small mammals from Liguanqiao basin of Henan Province and Yuanqu basin of Shanxi Province, Central China. Palaeontologica Sinica, 18 New Series C, 26: $1-256$

Tsubamoto T., Takai M., Shigehara N., Egi N., Tun, S.T., Aung A.K., Maung M., Danhara T., and Suzuki H. (2002) Fissiontrack zircon age of the Eocene Pondaung Formation, Myanmar. Journal of Human Evolution, 42: 361-369.

Tsubamoto T., Takai M., and Egi N. (2004) Quantitative analyses of the middle to late Eocene mammalian faunas in East Asia and inferences on regional differentiation of faunal evolution. Journal of Vertebrate Paleontology (in press).

Wang B. and Li C. (1990) First Paleogene mammalian fauna from northeast China. Vertebrata Palsiatica, 28: 165-205. 